\title{
AS RELACÕES ENTRE GOVERNANCA CORPORATIVA, RISCO E ENDIVIDAMENTO E SUAS INFLUENCIAS NO DESEMPENHO FINANCEIRO E NO VALOR DE MERCADO DE EMPRESAS BRASILEIRAS
}

\author{
João Carlos Hipólito Bernades do Nascimento' \\ Marcello Angotti ${ }^{2}$ \\ Marcelo Alvaro da Silva Macedo ${ }^{3}$ \\ Patricia Maria Bortolon ${ }^{4}$
}

\begin{abstract}
Resumo: O presente estudo analisou as relações entre Governança Corporativa, Risco e Endividamento e seus impactos no Desempenho Financeiro e no Valor das firmas. Com uma amostra composta por 639 observações de firmas brasileiras listadas na BM\&FBovespa, e tendo como recorte temporal o período de 2013 a 2015, utilizou-se a técnica PLS-SEM, em escalas formativas. A título de resultados, foi possível suportar as hipóteses de relacionamento entre Endividamento e Desempenho Financeiro, Endividamento e Risco, Desempenho Financeiro e Valor de Mercado e entre Endividamento e Governança nas análises compreendendo todas as observações e após a segmentação pelo porte das firmas. Através do controle do porte das firmas, foi possível corroborar ainda as relações entre Endividamento e Valor de Mercado, Risco e Desempenho Financeiro e entre Governança e Valor de Mercado apenas para empresas de maior tamanho. Complementarmente, os relacionamentos entre Risco e Valor de mercado, Governança e Desempenho Financeiro e entre Governança e Risco mostraram-se coerentes, especialmente, para empresas de menor tamanho, logo, o porte mostrou-se uma variável relevante para as teorizações analisadas. Por fim, após o controle do ano, notou-se que a instabilidade política e econômica, de forma significativa e sistemática, influenciou as relações teóricas, sendo, imprescindível, nesse aspecto, efetuar o controle do tempo quando o interesse for capturar as complexas relações simultâneas de dependência e independência entre Governança Corporativa, Risco, Estrutura de Capital, Desempenho e Valor da firma.
\end{abstract}

Palavras-chave: Governança Corporativa; Valor de Mercado; Desempenho Financeiro; PLS-SEM.

'jchbn1@gmail.com - Universidade Federal do Piauí

angotti@ufsj.edu.br - Universidade Federal de São João del-Rei

3 malvaro.facc.ufrj@gmail.com - Universidade Federal do Rio de Janeiro

${ }^{4}$ patricia.bortolon@ufes.br - Universidade Federal do Espírito Santo

- DOI: http://dx.doi.org/10.14392/asaa.201811010809

- Artigo premiado como melhor estudo do XI Congresso da Associaçăo Nacional de Programas de Pós-Graduação em Ciências Contábeis (Anpcont) e, como tal, foi convidado

a efetuar a submissão à ASAA Journal

- Artigo submetido em: 09/08/2017. Aceito em: 10/11/2017. 


\section{THERELATIONSHIPS AMONG CORPORATEGOVERNANCE, RISK AND DEBT AND THEIR INFLUENCES ON THE FINANCIAL PERFORMANCE AND MARKET VALUE OF BRAZILIAN COMPANIES}

Abstract: The present study analyzed the relationships among Corporate Governance, Risk and debt and its impacts on Financial Performance and Firms Value. With a sample composed by 639 observations of Brazilian companies listed on the BM\&FBovespa and using as a time-cut the period from 2013 to 2015, the PLS-SEM technique was used in formative scales. As a result, it was possible to support the relationship between Debt and Financial Performance, Debt and Risk, Financial Performance and Market Value and between Debt and Governance in the analyzis including all the observations and after the segmentation by the size of the firms. By controlling the size of firms, it was possible to corroborate the relationship between Debt and Market Value, Risk and Financial Performance and between Governance and Market Value only for larger companies. Complementarily, the relationships between Risk and Market Value, Governance and Financial Performance and between Governance and Risk were found to be consistent, especially for smaller companies, therefore, size was a relevant variable for the theories analyzed. Finally, after controlling for the year, it was noted that political and economic instability, in a significant and systematic way, influenced the theoretical relations, being essential, in this aspect, to control for the time when the interest is to capture the complex relations of dependence and independence between Corporate Governance, Risk, Capital Structure, Performance and Value of the firm.

Keywords: Corporate Governance; Market value; Financial Performance; PLS-SEM. 


\section{INTRODUÇÃO}

D arte relevante da literatura sobre a influência da Governança Corporativa no Risco, Desempenho Financeiro e no Valor de Mercado das firmas, costumeiramente, foi conduzida por meio de modelos que buscavam maximizar a variância explicada de uma única variável dependente frente a algumas variáveis explicativas, em uma única direção da causalidade. Análises do tipo impossibilitam, assim, uma compreensão mais abrangente das complexas relações simultâneas de dependência e independência entre as variáveis.

Nessa perspectiva, a técnica de Modelagem de Equações Estruturais, que permite o exame simultâneo de um conjunto de relacionamentos teóricos entre uma ou mais variáveis independentes frente a uma ou mais variáveis dependentes (Tabachnick \& Fidell, 1996), tem sido recentemente aplicada como uma alternativa a essa abordagem tradicional via Regressões por MQO. Diante do exposto, a exemplo de Adi, Siti e Rahayu (2013), buscou-se, no presente estudo, analisar as relações entre Governança Corporativa, Risco e Endividamento e seus impactos no Desempenho Financeiro e no Valor das firmas. Para tal, foi utilizada a técnica de Equações Estruturais em Mínimos Quadrados Parciais (Partial Least Squares - Structural Equation Modeling - PLS-SEM) com escalas de mensuração formativas aplicada a uma amostra de companhias brasileiras não financeiras listadas na BM\&FBOVESPA.

Em termos de resultados, foram obtidos indícios empíricos que permitem suportar os relacionamentos previstos entre 'Endividamento' e ‘Desempenho Financeiro,' 'Endividamento' e 'Risco,' 'Desempenho Financeiro' $\mathrm{e}$ 'Valor de Mercado' e entre'Endividamento'e 'Governança' nas análises compreendendo todas as observações e após a segmentação pelo porte das firmas. Por meio do controle do porte das firmas, notou-se que as relações entre 'Endividamento' e'Valor de Mercado,',Risco' e 'Desempenho Financeiro'e entre 'Governança' e 'Valor de Mercado' são corroboradas apenas para as empresas de maior porte, enquanto que os relacionamentos entre'Risco'e'Valor de mercado,',Governança'e' $\mathrm{e}^{\prime}$ Desempenho Financeiro' e entre 'Governança' e'Risco' confirmam-se apenas para as firmas de menor tamanho, logo, são obtidos indícios empíricos de que o porte mostra-se uma variável relevante para as teorizações analisadas. Por fim, notou-se, após o controle do'ano', que a instabilidade política e econômica vivenciada pelo país no período analisado influenciou, de forma significativa e sistemática, as relações teóricas, sendo, nesse aspecto, imprescindível efetuar o controle do tempo quando o interesse for capturar as complexas relações simultâneas de dependência e independência entre Governança Corporativa, Risco, Estrutura de Capital, Desempenho e Valor da firma.

O presente estudo se diferencia do paper de Adi, Siti e Rahayu (2013) ao contemplar uma amostra mais abrangente, com 639 firmas, tendo em vista que aquele engloba apenas 23 firmas do setor de mineração da Indonesia Stock Exchange. Distingue-se, também, ao buscar compreender as variáveis de controle (Porte e Ano) e por realizar testes de robustez (Robust Path Analysis). Ademais, vários fatores conjunturais diferenciam o mercado de capitais brasileiro, como a complexa estrutura tributária, uma predominância de estrutura familiar na gestão, os elevados custos de oportunidade dos investidores, dentre outros.

Justifica-se a condução da presente investigação por contribuir com a compreensão mais abrangente acerca das complexas relações simultâneas de dependência e independência entre Governança Corporativa, Risco, Endividamento, Desempenho Financeiro e Valor de Mercado da firma, ressaltando a 
importância relativa e o desempenho real de cada construto, bem como os efeitos diretos, indiretos e totais existentes entre esses construtos, lacuna essa pouco explorada pela literatura.

Além dessa Introdução, são reportadas quatro seções. Inicialmente a literatura é revisada buscando suporte para o desenvolvimento das dez hipóteses de pesquisas. A seguir, são reportados os procedimentos adotados para coleta e análise dos dados. No quarto tópico são realizadas as análises dos dados e, por fim, no quinto e último tópico, são postas as considerações finais com as respectivas limitações e indicações de oportunidades para o desenvolvimento de futuras pesquisas.

\section{DESENVOLVIMENTO DAS HIPÓTESES}

Em um "mercado perfeito", onde todos os agentes têm igual acesso às informações, que são obtidas a custo zero, e inexistem custos de transações ou impostos, conforme proposto por Modigliani e Miller (1958), a forma como as firmas se financiam seria irrelevante para o valor da empresa. Posteriormente, Modigliani e Miller (1963) reconhecem o efeito do benefício fiscal da dívida e consequentemente que é possível elevar o valor da empresa através da alavancagem.

O limite ao benefício fiscal do endividamento encontra-se nos custos diretos e indiretos de falência, levando ao desenvolvimento da Teoria do Trade-Off (Kraus \& Litzenberger, 1973). A introdução das questões relacionadas à assimetria de informações na decisão de financiamento das empresas é a base da Pecking Order Theory (POT).

De acordo com a Pecking Order Theory (POT), as firmas seguem uma sequência hierárquica no estabelecimento da estrutura de capital, partindo do financiamento interno (preferencialmente), títulos da dívida, até a emissão de ações (em um continuum), sendo as firmas mais lucrativas naturalmente menos endividadas, dado que estas podem financiar seus projetos sem a necessidade de contrair dívidas e/ou emitir ações (Myers \& Majluf, 1984). Diante do exposto, é formulada a primeira hipótese de pesquisa:

$\mathrm{H}_{1}=$ existe uma relação negativa entre Endividamento da empresa e o seu Desempenho Financeiro.

O pressuposto inerente à POT é que as decisões de estrutura de capital são exercidas hierarquicamente, buscando maximizar a utilidade de dois stakeholders específicos: administradores e acionistas. Ao optarem por uma forma específica de financiamento, os gestores consideram variáveis diversas, como, por exemplo, o custo de capital e as condições de mercado, sendo, porém, o impacto da assimetria informacional no mercado a mais relevante (lquiapaza, Amaral, \& Araújo, 2008).

Dado que os recursos gerados internamente, em tese, são menos suscetíveis de apresentar maiores problemas de assimetria informacional, quando comparados às demais formas de captação de recursos (Myers \& Majluf, 1984), ao optarem por emitir dívidas para financiar projetos, os gestores são questionados pelos acionistas, em resposta à assimetria informacional, sobre os motivos para a não utilização de recursos gerados internamente em detrimento de oriundos de captação externa. Tal fato acarreta numa subavaliação das ações e, consequentemente, na perda de valor para os acionistas em resposta à decisão (Medeiros \& Daher, 2008).

Ao elevar o nível da dívida, consequentemente, a firma tem seu risco específico majorado, uma vez que os compromissos assumidos pressionam o caixa, incrementando, assim, o risco de falência. Esse cenário de incremento da dívida e, portanto, de elevação do risco, faz com que os problemas de agência para acionistas e credores se agravem (Fama \& French, 1998). Além disso, em algum momento, firmas com alto endividamento deixarão passar oportunidades de investimento valiosas que, eventualmente, 
poderiam incrementar a peformance da empresa, logo, a alta alavancagem é uma má notícia que influencia negativamente o valor de marcado da empresa (Jensen \& Meckling, 1976; Myers, 1977).

As decisões de financiamento das empresas funcionam como dispositivos de sinalização/transmissão de informações aos stakeholders acerca dos riscos do negócio e da sua rentabilidade. Nessa perspectiva, a emissão de dívida de risco reduz o valor de mercado atual da empresa por meio da indução de uma estratégia de futuro que é subótima, sendo a perda de valor de mercado absorvida pelos acionistas atuais da firma (Myers, 1977). Assim, formulam-se a segunda e terceira hipóteses de pesquisa:

$\mathrm{H}_{2}$ = existe uma relação negativa entre o Endividamento da empresa e o seu Valor de Mercado.

$\mathrm{H}_{3}$ = existe uma relação positiva entre o Endividamento da empresa e o Risco específico.

Após o estudo pregresso de Ball e Brown (1968) acerca da relação entre a informação contábil e as respostas por parte do mercado, uma série de estudos foram conduzidos ampliando o conhecimento acerca do relacionamento entre o resultado contábil e os preços das ações (eg., Brown, 1970; Foster, 1975; Beaver, Clark \& Wright, 1979; Firth, 1981). Nessa perspectiva, a Abordagem Informacional (Information Approach) preconiza que a informação contábil apresenta relevância e utilidade para as decisões de seus usuários.

Segundo a Hipótese do Mercado Eficiente (HME), as oscilações dos preços das ações incorporam e refletem toda a informação disponível e expectativas acerca das empresas (Fama, 1991), logo, ao reportar bons resultados, o mercado ajusta-se refletindo essa boa notícia nos preços das ações. Nessa linha, Demsetz e Villalonga (2001) notaram uma correlação positiva entre o desempenho financeiro com o valor da empresa. Chung et al. (2003) corroboraram a correlação positiva entre o valor da empresa com o desempenho (medido pela lucratividade). Assim, diante desses achados, formula-se a quarta hipótese de pesquisa:

$\mathrm{H}_{4}=$ existe uma relação positiva entre o Desempenho Financeiro da empresa e o seu Valor de Mercado.

O risco pode ser segmentado em risco sistêmico ou de mercado, que é não diversificável e inerente à conjuntura na qual as empresas atuam, e risco específico ou unitário, que é diversificável e restrito especificamente à firma. Muito embora ambos os riscos sejam, geralmente, correlacionados (Weston \& Brigham, 2000), o risco específico da firma, além de absolver parte do risco sistêmico, especialmente do setor em que opera, é bastante sensível ao grau de alavancagem financeira aceito (Damodaran, 2002), tendo em vista que, ao passo que a firma incrementa seu nível de endividamento frente ao patrimônio líquido, o risco de inadimplência (específico) é elevado.

Nessa perspectiva, inicialmente, vários estudos evidenciaram que o risco específico da firma está negativamente relacionado ao valor de mercado e positivamente relacionado com o desempenho financeiro (e.g. Ben-Zion, 1978; Hirschey, 1982; Jose, Nichols, \& Stevens, 1986). Mais recentemente, Chung et al. (2003), além de corroborar a correlação positiva entre o valor da empresa, tendo como proxy o Q de Tobin, com o desempenho (medida pela lucratividade), observaram que o valor da empresa é negativamente associado com o risco. Especificamente acerca da relação entre risco e o desempenho financeiro da empresa, Fama e French (2002), Chung, Wright e Kedia (2003) e Mule e Mukras (2015), concluíram pela existência de uma relação negativa. Adiante do exposto, são formuladas a quinta e sexta hipóteses.

$\mathrm{H}_{5}=$ existe uma relação negativa entre o Risco específico da empresa e o seu Desempenho Financeiro.

$\mathrm{H}_{6}=$ existe uma relação negativa entre Risco específico da empresa e o seu Valor de Mercado.

Em função da discricionariedade dos gestores em um ambiente de dispersão acionária e a consequente assimetria informacional, Berle e Means (1932) abordaram o problema do risco moral (moral hazard) - e.g., esforço insuficiente, benefícios privados, investimentos pouco eficientes e/ou extravagantes, 
estratégias de entrincheiramento, manipulações contábeis - inerente da segregação entre propriedade e controle, acarretando, assim, no surgimento de conflitos de agência entre stakeholders, sobretudo entre acionistas e gestores (Tirole, 2010).

Diante desse cenário, a governança corporativa mostra-se um meio importante para mitigar conflitos de agência, na medida em que aproxima os interesses dos insiders e outsiders. Nessa perspectiva, a literatura tem evidenciado a existência de uma relação positiva entre governança corporativa e valor da empresa. Por exemplo, Gompers, Ishii e Metrick (2003) notaram a existência de correlação significativa entre governança corporativa (capturado através de um índice - Governance Index) e várias proxys de desempenho como os retornos das ações, $\mathrm{Q}$ de Tobin, valor da firma, o crescimento das vendas e dos lucros. Os autores concluíram ainda que firmas com maiores níveis de Governança Corporativa, medida por direitos dos shareholders, têm altos valores de mercado, alta rentabilidade e crescimento de vendas, baixo custo de capital e tendem a fazer aquisições corporativas.

Klapper e Love (2004) notaram a existência de relação positiva entre governança corporativa, valor de mercado e desempenho das firmas. Com uma amostra composta por firmas norte-coreanas, Black, Jang e Kim (2003) também concluíram que firmas com boas práticas de governança apresentam maior valor de mercado. Sami, Wang e Zhou (2011) indicaram a existência de uma correlação positiva significativa entre a governança corporativa e o desempenho das firmas. Ulum, Wafa, Karim e Jamal (2014) afirmam que um sistema eficaz de governança corporativa é fundamental para melhorar o desempenho de uma empresa. Nesse ponto, são formuladas a sétima e oitava hipóteses de pesquisa.

$\mathrm{H}_{7}=$ existe uma relação positiva entre o nível de Governança Corporativa e o seu Desempenho Financeiro.

$\mathrm{H}_{8}=$ existe uma relação positiva entre o nível de Governança Corporativa e Valor de Mercado da firma.

A redução do caixa disponível, resultante de um maior nível de endividamento, acarreta em menor discricionariedade por parte dos gestores, dado que a geração de caixa deve ser suficiente para exceder todas as obrigações, sob risco de dificultar novas contratações de financiamentos, reduzindo as oportunidades de "desvios", exercendo, assim, um efeito disciplinador (Tirole, 2010). No entanto, essa conjuntura pode acarretar em um efeito substituição, isto é, com maiores esforços de monitoramento por parte dos detentores da dívida, pode haver menor necessidade da firma investir em melhores mecanismos de governança. Jiraporn e Gleason (2007) indicam, de modo consistente com a teoria de agência, que há uma relação negativa entre os direitos dos acionistas e a alavancagem financeira, apontando que nas empresas em que esses direitos são fracos há maior nível de endividamento. Diante do exposto, formula-se a nona hipótese de pesquisa:

$\mathrm{H}_{9}$ = existe uma relação negativa entre o Endividamento da empresa e o seu nível de Governança Corporativa.

Boas práticas de Governança Corporativa, fundamentadas nos princípios de transparência (disclosure), equidade (fairness) para com os stakeholders, prestação de contas (accountability) e observância ao cumprimento das legislações (compliance), mostram-se eficientes mecanismos de minimização de riscos (Silva, 2005). Dado o cenário de assimetria informacional decorrente da segregação entre propriedade e gestão, a maior transparência decorrente da existência de boas práticas de Governança Corporativa acarreta na redução substancial do risco específico da empresa percebido pelo investidor (Assaf Neto, 2012; Silveira, 2015). Nessa perspectiva, alguns estudos têm focado em analisar a relação entre Governança e Risco específico da firma. Prasetyo (2011) notou que, no longo prazo, firmas com elevado nível de Governança Corporativa têm seus riscos específicos minimizados, concluindo, assim, que há um impacto negativo sobre a sensibilidade dos retornos ao risco específico da firma. 
Nessa mesma linha, em um estudo com uma amostra composta por companhias abertas brasileiras Lameiras (2012) concluiu que variações na qualidade da governança corporativa relacionaram-se inversamente com o risco das firmas. Diante dos achados da literatura, formula-se a décima hipótese:

$\mathrm{H}_{10}=$ existe uma relação negativa entre o nível de Governança Corporativa e o Risco específico da empresa.

O modelo estrutural, construído pautado na literatura e teorias apresentadas, é apresentado na Figura 1, com as respectivas hipóteses de relacionamentos entre os construtos:

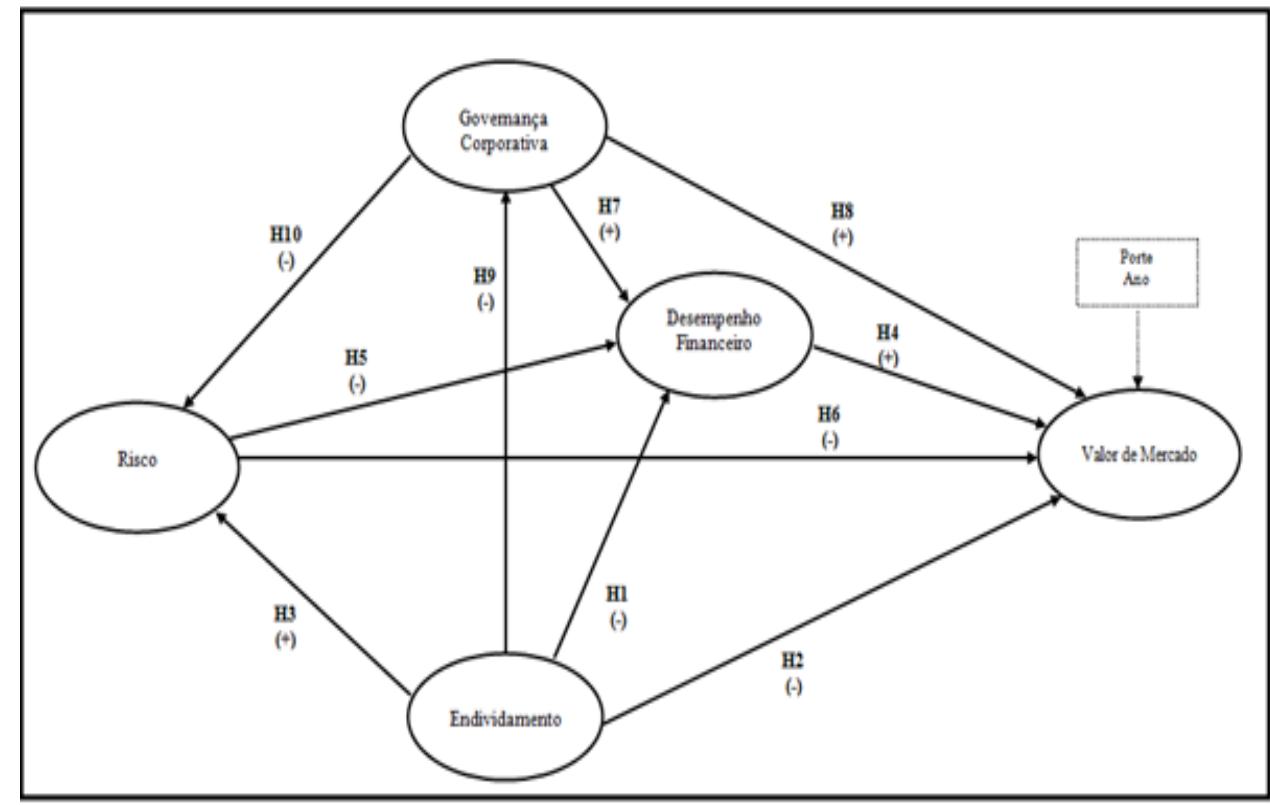

Figura 1: Modelo estrutural e hipóteses formuladas. Fonte: Elaborado pelos autores.

\section{MÉTODO}

A presente pesquisa apresenta um enfoque predominantemente quantitativo, de natureza descritiva e explicativa (Smith, 2003). A base de dados foi composta por 639 observações firmas/ano listadas na BM\&FBOVESPA. Essa amostra corresponde a cerca de $65 \%$ do valor de mercado das companhias listadas, e inclui 87 das 95 empresas mais negociadas na bolsa (IBRx-100). Não foram abrangidas as instituições financeiras e firmas com informações incompletas ou não disponíveis (acarretando a inexistência de missing values), sendo a amostra constituída da seguinte forma: 209 empresas no ano de 2013; 224 em 2014; e 206 em 2015. Os dados foram coletados nas bases de dados da Comissão de Valores Mobiliários (CVM), da BM\&FBovespa, da Economática ${ }^{\circledR}$ e da Comdinheiro.com ${ }^{\circledR}$.

Acerca do dimensionamento da amostra, Smith e Langfield (2004) sugerem 200 observações para a realização de inferências. Adicionalmente, considerando tamanho o efeito $(0,15)$, a probabilidade de erro do tipo a de 0,05 e o nível de potência estatística de 0,80, obteve-se uma solução com 201 observações. Logo, como 639 observações compuseram análise, conclui-se pela inexistência de problemas de dimensionamento da amostra. Na Tabela 1 reportam-se os setores que compõem a amostra ano a ano. 
Tabela 1: Observações empresas/ano por setor do Economática ${ }^{\circledR}$

\begin{tabular}{|c|c|c|c|c|c|}
\hline Setor & 2013 & 2014 & 2015 & Total & $\%$ \\
\hline Outros & 53 & 56 & 53 & 162 & $25 \%$ \\
\hline Energia Elétrica & 22 & 30 & 22 & 74 & $12 \%$ \\
\hline Construção & 18 & 18 & 16 & 52 & $8 \%$ \\
\hline Comércio & 13 & 14 & 17 & 44 & $7 \%$ \\
\hline Têxtil & 15 & 15 & 11 & 41 & $6 \%$ \\
\hline Siderurgia e Metalurgia & 13 & 13 & 14 & 40 & $6 \%$ \\
\hline Alimentos e Bebidas & 11 & 13 & 11 & 35 & $5 \%$ \\
\hline Transporte Serviços & 10 & 10 & 11 & 31 & $5 \%$ \\
\hline Veículos e peças & 11 & 11 & 10 & 32 & $5 \%$ \\
\hline Demais Setores & 43 & 44 & 41 & 128 & $20 \%$ \\
\hline Total & 209 & 224 & 206 & 639 & $100 \%$ \\
\hline
\end{tabular}

Fonte: Dados da pesquisa

Como técnica de análise de dados foi utilizada a Modelagem de Equações Estruturais (Structural Equation Models - SEM). Dado que o estudo foi operacionalizado por meio da coleta de dados secundários, foi adotada a abordagem PLS-SEM com a utilização de escalas de mensuração formativas. Nas escalas de mensuração formativa, o construto é resultante da ocorrência de múltiplas variáveis intermutáveis (cada uma capturando um aspecto específico) (Rodgers, 1999). Logo, é muito importante que os indicadores capturem todas as facetas do construto (ou pelo menos as mais importantes) de forma a garantir que seu conteúdo seja adequadamente capturado (Diamantopoulos \& Winklhofer, 2001). De tal modo, para fins de operacionalização das variáveis, foram adotadas proxys consolidadas na literatura, conforme reportado no Quadro 1.

Tabela 1: Observações empresas/ano por setor do Economática ${ }^{\circledR}$

\begin{tabular}{|c|c|c|}
\hline \multicolumn{3}{|c|}{ Painel A: Variáveis formativas de cada construto } \\
\hline Construto & Variáveis & Sigla \\
\hline Endividamento & Endividamento Total $=$ Passivo Total $/$ Ativo Total & End \\
\hline Risco & $\begin{array}{l}\text { Alfa de Jensen } \\
\text { Beta } \\
\text { Prejuízo: dummy }=1 \text { se houve prejuízo em pelo menos } 2 \text { anos no período observado } \\
\text { Variação nos últimos } 12 \text { meses do Fluxo de Caixa Operacional } \\
\text { Variação nos últimos } 12 \text { meses do lucro líquido } \\
\text { Volatilidade dos retornos das açôes nos últimos } 12 \text { meses } \\
\text { Correlação dos retornos das ações com IBOVESPA (apenas para análise de redundância) }\end{array}$ & $\begin{array}{l}\text { Alfa } \\
\text { Beta } \\
\text { Prej2 } \\
\text { vFCO } \\
\text { vLL } \\
\text { VOL } \\
\text { Correl }\end{array}$ \\
\hline Desempenho Financeiro & $\begin{array}{c}\text { EBITDA sobre a Receita } \\
\text { Fluxo de caixa operacional (FCO) ponderado pelo Ativo Total } \\
\text { Giro dos Ativos } \\
\text { ROE } \\
\text { ROA (apenas para análise de redundância) }\end{array}$ & $\begin{array}{l}\text { EbitRec } \\
\text { FCOAT } \\
\text { GiroAT } \\
\text { ROE } \\
\text { ROA }\end{array}$ \\
\hline Valor de Mercado & Logaritmo Natural (LN) do Valor de Mercado & VM \\
\hline Governança Corporativa & $\begin{array}{c}\text { Percentual de Free float On } \\
\text { Percentual de Free float Total } \\
\text { Conselho de Administração: dummy }=1 \text {, quando o tamanho é adequado ao } \\
\text { recomendado pelo IBGC } \\
\text { Segmento: dummy }=1 \text { se Novo Mercado ou Nível } 2 \\
\text { Tag Along On: dummy }=1 \text { se direitos além do mínimo legal } \\
\text { Proxy de Governança (apenas para análise de redundância) }\end{array}$ & $\begin{array}{l}\text { FFON } \\
\text { FFT } \\
\text { MTCA } \\
\text { Segm } \\
\text { TAOn } \\
\text { PGC }\end{array}$ \\
\hline \multicolumn{3}{|c|}{ Painel B: Variáveis de Controle } \\
\hline Variáveis de Controle & $\begin{array}{c}\text { Porte }(\operatorname{tamanho})=\operatorname{Ln} A T \\
\text { Ano }\end{array}$ & $\begin{array}{l}\text { Porte } \\
\text { Ano }\end{array}$ \\
\hline
\end{tabular}

Fonte: Elaborada a partir dos dados da pesquisa

No grupo de indicadores do construto'Risco'tem-se sete variáveis. As variáveis'Alfa de Jensen,'Beta', 'Volatilidade' e 'Correlação' (essa última utilizada, apenas, para a realização da análise de redundância) foram obtidas por meio do software Economática ${ }^{\oplus}$. Para a obtenção desses indicadores foram configurados como parâmetros séries de cotações diárias, no período de dois anos anteriores à data base, tendo como benchmark o IBovespa e, como taxa livre de risco, a taxa Selic. Completando o construto 'Risco', tem-se ainda a'Variação do Fluxo de Caixa Operacional'e'Variação do Lucro Líquido' no exercício 
corrente, que consistem na variação percentual do $\mathrm{FCO}$ e do $\mathrm{LL}$ em relação ao ano anterior ([t2-t1]/t1); e uma variável dummy que assume o valor 1 para as firmas que apresentaram prejuízos em pelo menos dois anos do período analisado, ou o valor 0 em caso contrário.

O construto 'Desempenho financeiro' compreende cinco variáveis: o 'EBITDA sobre a Receita', ou seja, o resultado operacional na forma percentual das receitas líquidas operacionais; a capacidade de geração de caixa, capturada pelo 'Fluxo de Caixa Operacional (FCO) sobre o Ativo Total'; o 'Giro dos Ativos', representando o volume de vendas a partir dos ativos operacionais; o Retorno medido pela divisão do lucro líquido sobre o Patrimônio Líquido médio, 'ROE'; e o Retorno sobre os Ativos, 'ROA', obtido pela divisão do resultado operacional pelos ativos médios (essa última utilizada, apenas, para a realização da análise de redundância).

Para'Governança Corporativa', foram utilizadas seis variáveis, sendo cinco obtidas por meio da base do portal Comdinheiro.com ${ }^{\oplus}$, e uma variável proxy para indicar empresas com maior expectativa de apresentarem melhores práticas de governança. Fazem parte do construto os seguintes indicadores: 'Percentual de Free float On'e'Percentual de Free float Total', que representam a quantidade percentual de ações ordinárias e totais livres à negociação no mercado; uma variável dummy que assume valor igual a 1 se o tamanho do Conselho de Administração é adequado à recomendação do IBGC de no mínimo 5 e no máximo 9 membros (IBGC, 2015); a variável'Segmento', que é uma dummy que assume valor igual a 1 (um) quando a empresa está listada no segmento Novo Mercado ou Nível 2, ou 0 (zero) em cenário contrário. Outra variável binária foi utilizada para identificar as companhias que garantem direitos de 'Tag Along', além daqueles legalmente exigidos. Finalmente, utilizou-se um conjunto de variáveis como uma proxy (PGC) para representar companhias com melhores práticas de governança corporativa, que consiste na soma de dummies que indicam: se a empresa é auditada por uma Big4, se a empresa emite ADR's e se a empresa participa dos índices diferenciados de governança da BM\&FBovespa (IGCX, ITAG, IGCT e IGC-NM), sendo essa última variável (PGC) utilizada, apenas, para a realização da análise de redundância. Acerca das variáveis endógenas, 'Endividamento Total'foi calculado por meio do Passivo Total dividido pelo Ativo Total (Passivo Circulante + Passivo não Circulante / Ativo total), enquanto'Valor de mercado' foi operacionalizado através do cálculo do logaritmo natural do resultado da multiplicação da cotação das ações (cada classe) pelo número de ações.

Em modelos PLS-SEM os relacionamentos de causa e efeito partem do pressuposto de que as variáveis latentes exógenas são diretamente afetadas por varáveis latentes endógenas sem a sistemática influência de outras variáveis (Hair Jr. et al., 2014), assim, optou-se por controlar o porte das firmas e o ano das demonstrações.

Conforme apresentado anteriormente, foi utilizada a técnica PLS-SEM, em decorrência da abordagem essencialmente exploratória do presente estudo e, sobretudo, em decorrência da não linearidade das relações entre as variáveis, o que demandou a utilização do algoritmo baseado em fator (Factor-Based PLS Type REG1), que combina a precisão dos algoritmos SEM, à base de covariância, com as características não-paramétricas de algoritmos PLS clássicos, sendo, nesse aspecto, considerado o mais próximo de projeto original de PLS proposto por Wold (Kock, 2015).

\section{ANÁLISE DOS DADOS}

As estatísticas descritivas de tendência central e dispersão das observações são reportadas na Tabela 2. 
Tabela 2: Estatística descritiva da amostra completa

\begin{tabular}{|c|c|c|c|c|c|}
\hline Variável & $1{ }^{\circ}$ Quartil & Média & Mediana & 3Quartil & Desvio padrão \\
\hline Endividamento & 46,48 & 65,84 & 58,48 & 75,14 & 50,18 \\
\hline Alfa & $-19,27$ & 17,68 & 0,01 & 24,58 & 91,74 \\
\hline Beta & 0,24 & 0,47 & 0,41 & 0,66 & 0,36 \\
\hline Variação FCO & $-0,28$ & $-0,13$ & 0,04 & 0,28 & 5,61 \\
\hline Variação LL & $-0,63$ & $-0,60$ & $-0,06$ & 0,33 & 13,05 \\
\hline Volatilidade & 29,34 & 44,87 & 35,83 & 50,85 & 37,79 \\
\hline Correlação & 0,12 & 0,27 & 0,24 & 0,41 & 0,19 \\
\hline EBITDA/Receita & 0,03 & 0,08 & 0,10 & 0,18 & 3,20 \\
\hline FCO AT & 0,04 & 0,09 & 0,09 & 0,14 & 0,22 \\
\hline Giro dos Ativos & 0,30 & 0,64 & 0,52 & 0,87 & 0,53 \\
\hline ROA & $-1,51$ & 0,44 & 2,73 & 6,33 & 15,73 \\
\hline ROE & $-0,11$ & 0,25 & 6,41 & 14,64 & 41,77 \\
\hline Ln Valor de Mercado & 12,44 & 13,93 & 14,22 & 15,44 & 2,14 \\
\hline FFON & 1,41 & 15,79 & 9,74 & 26,48 & 17,38 \\
\hline FFT & 6,44 & 24,73 & 23,14 & 37,59 & 20,57 \\
\hline Ln AT & 13,77 & 14,90 & 15,04 & 16,02 & 1,88 \\
\hline
\end{tabular}

Fonte: Elaborada a partir dos dados da pesquisa

Foram excluídas as variáveis dummies que, por serem binárias, não são apropriadas para a realização dessa análise. Para esses casos aponta-se aqui a frequência relativa em que a variável binária foi igual a 1: 30,0\% das observações de Prej2; 70,6\% para MTCA; 54,3\% para Segm; e 75,7\% para TAOn. De forma geral, observa-se, como é comum em amostras amplas, uma ampla dispersão, indicando a heterogeneidade presente nos dados (o que reforçou a necessidade de controle das variáveis "Porte" e "Ano").

\subsection{Avaliação do modelo de mensuração}

Inicialmente, avaliou-se a validade convergente através da Análise de Redundância. Os valores estimados de $R^{2}$ de 0,894, 0,985 e 0,815 para os construtos Risco, Desempenho Financeiro e Governança Corporativa, respectivamente, permitiram concluir que todos os construtos de medidas formativas apresentam graus suficientes de validade convergente - espera-se uma magnitude de, pelo menos, 0,80 para o caminho existente entre o construto formativo e o reflexivo (Chin, 1998). Ressalta-se que não foi realizada a análise de convergência dos construtos 'Endividamento' $e^{\prime} V a l o r$ de mercado' pelo fato destes serem constituídos por itens únicos. No entanto, este tipo de construto é claramente adequado quando utilizado para medir características diretamente observáveis, tais como vendas, quotas, lucros, e assim por diante (Fuchs \& Diamantopoulos, 2009; Diamantopoulos, Sarstedt, Fuchs, Kaiser, \&Wilczynski, 2012). Adicionalmente, ressalta-se que, quando se trabalha com modelos de mensuração formativos, não existem problemas para a estimação de construtos formados por um ou dois itens (Hair Jr. et al, 2014).

Assegurada a existência de validade convergente, as atenções se voltam para a avaliação da colinearidade entre os indicadores de cada construto. Diferentemente da abordagem reflexiva, não há expectativas sobre padrões ou magnitude de intercorrelações entre os indicadores quando se utilizam modelos de mensuração formativos, dado que há "causa comum" para os itens do construto (Diamantopoulos, Riefler, \& Roth, 2008). Diante do exposto, através da análise das estatísticas de colinearidade dos indicadores dos construtos Risco, Desempenho Financeiro e Governança Corporativa, conclui-se pela inexistência de problemas de colinearidade relevante entre os indicadores compreendidos nos seus respectivos construtos latentes dado que todos apresentaram valor de Variance Inflation Factor (VIF) inferiores a 2,2, logo, bem abaixo do teto de 5 proposto na literatura. 
$\mathrm{Na}$ análise do peso externo, notou-se que os indicadores de todas as variáveis latentes apresentaram sinais do carregamento dos pesos (Indicator Weight Loading Signs - WLS) positivos, indicando a inexistência do paradoxo de Simpson (Pearl, 2009; Wagner, 1982). Acerca do tamanho do efeito de cada indicador ( $\left.\mathrm{f}^{2}\right)$, calculado como o valor absoluto da contribuição individual, foi possível concluir que, com exceção de'vFCO' e'vLL', do construto'Risco', e'EbitRec'e 'GiroAt', do construto'Desempenho Financeiro', as variáveis mostraram-se estatisticamente significantes ao nível de, pelo menos, 0,05. Segundo Hair Jr. et al., 2014, a utilização de muitos indicadores incrementa a probabilidade de ser obtidos pesos externos baixos ou até mesmo não significantes (Hair Jr. et al., 2014). Nesse aspecto, torna-se relevante considerar a contribuição absoluta do indicador formativo para o construto, ou seja, a informação que o indicador fornece sem considerar quaisquer outros indicadores.

Diferente dos pesos externos, as cargas externas decorrem de regressões individuais de cada indicador frente ao construto latente correspondente (equivalente ao teste de correlação e entre cada indicador e o constructo). Segundo Hair Jr. et al. (2014), quando o peso externo do indicador é não significativo, mas a sua carga externa é elevada $(>0,50)$, o indicador deve ser interpretado como relativamente importante, sendo o indicador mantido. Utilizando esse critério (carga externa superior a 0,50 ), bem como o tamanho do efeito de cada indicador (que deve ser igual ou superior a 0,02), notou-se que as quatro variáveis que apresentaram pesos não significativos ('vFCO', 'vLL', 'EbitRec', e 'GiroAt') seriam candidatas à exclusão, dado que apresentaram, também, cargas externas não significantes. No entanto, Hair Jr. et al. (2014) sugerem que o pesquisador deve decidir se mantém ou não o indicador examinando sua relevância teórica, isto é, alinhamento frente a pesquisas anteriores e a teoria. Assim, optou-se por manter os referidos indicadores formativos para as análises subsequentes.

\subsection{Avaliação do ajuste do Modelo Estrutural e teste das hipóteses}

Concluída a análise do modelo de mensuração, avaliou-se o ajuste do modelo estrutural e, por conseguinte, segui-se para o teste das hipóteses delineadas na pesquisa. Na Figura 2, são reportados os resultados das hipóteses, bem como as medidas de qualidade de ajuste do modelo estrutural. Inicialmente, conforme pode ser observado no rodapé da Figura 2, o modelo estrutural proposto apresentou excelente capacidade preditiva e explicativa (APC, ARS, AARS e GoF), inexistência de problemas de multicolinearidade (AVIF e AFVIF), ausência do paradoxo de Simpson (SPR) e adequação das direções previstas para as relações do modelo em decorrência da estimação dos coeficientes não-lineares (NLBCDR).

Avaliando o grau de explicação da variância da variável endógena alvo, 'Valor de Mercado,' pode-se concluir que as quatro variáveis latentes analisadas ('Governança,',Risco,' 'Desempenho Financeiro'e'Endividamento'), consubstanciadas das variáveis de controle ('Porte' $\mathrm{e}$ 'Ano'), apresentam poder explicativo elevado da variância de 'Valor de Mercado' ( $R^{2}$ de 0,85 ). Acerca da validade preditiva (ou importância) associada a cada construto latente, foram obtidos coeficientes $\mathrm{Q}^{2}$ de Stone-Geisser, medida não-paramétricas calculadas via procedimento Blindfolding, de 0,045, 0,244, 0,234 e 0,861 para 'Governança', 'Risco,' 'Desempenho Financeiro' e'Valor de Mercado', respectivamente. Muito embora o coeficiente $\mathrm{Q}^{2}$ possa assumir valores negativos, considera-se que aceitáveis construtos latentes endógenos que apresentem coeficientes $\mathrm{Q}^{2}$ maior do que zero, assim, pode-se concluir que todos os construtos analisados apresentam níveis de validade preditiva satisfatórios. 


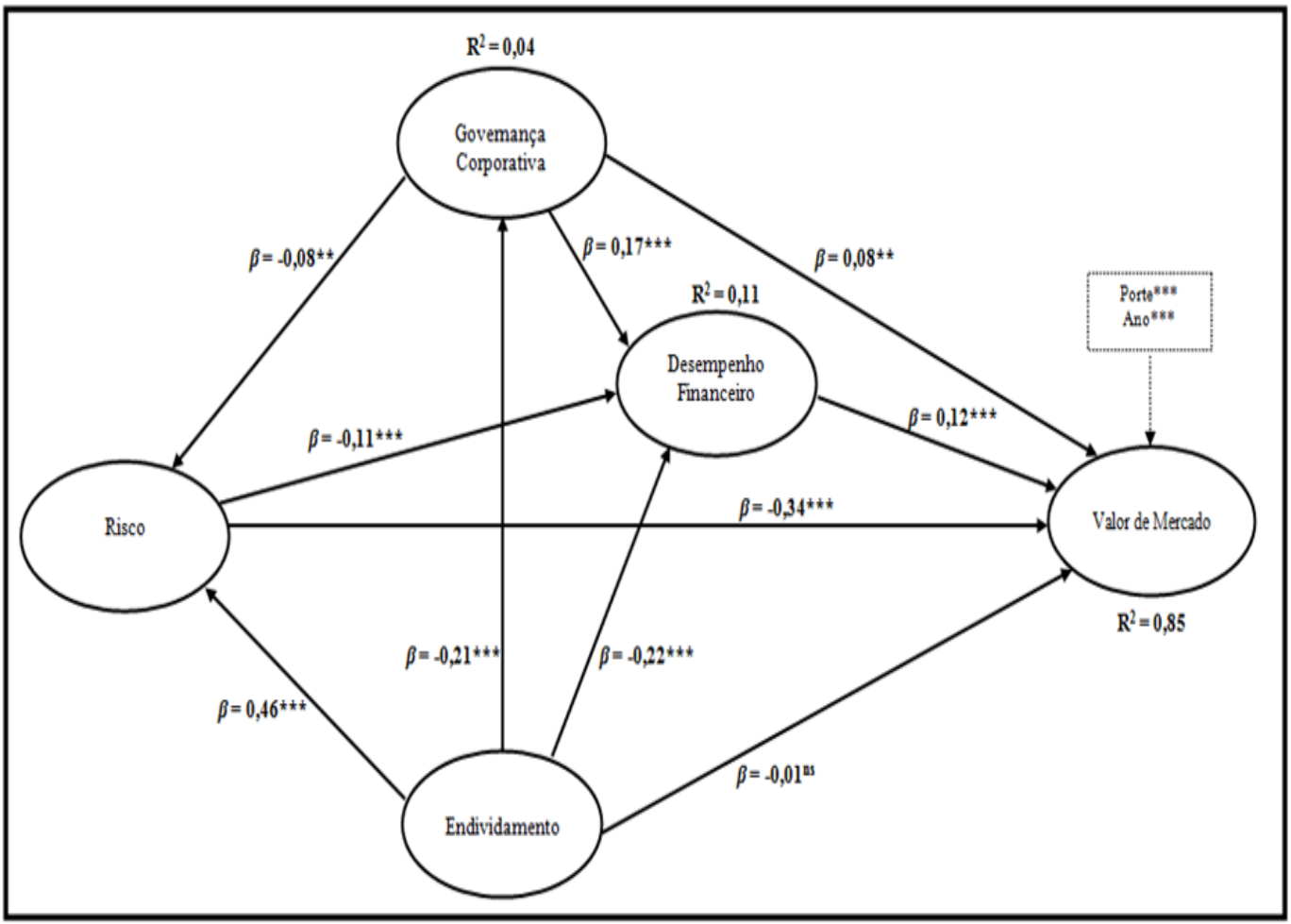

Figura 2 - Resultados do modelo estrutural para a amostra completa.

Fonte: Elaboração própria baseada nas saídas do software PLS utilizado

Notas: Average path coefficient $(A P C)=0.223(P<0.001)$; Average $R$-squared $(A R S)=0.329(P<0.001)$; Average adjusted $R$-squared $(A A R S)=0.327(P<0.001)$; Average block VIF $($ AVIF $)=1.293$, acceptable if $<=5$, ideally $<=3.3$; Average full collinearity VIF $(A F V I F)$ $=1.759$, acceptable if $<=5$, ideally $<=3.3$; Tenenhaus $\mathrm{GoF}(\mathrm{GoF})=0.488$, small $>=0.1$, medium $>=0.25$, large $>=0.36$; Sympson's paradox ratio $(S P R)=1$, acceptable if $>=0.7$, ideally $=1 ; R$-squared contribution ratio $(R S C R)=1$, acceptable if $>=0.9$, ideally $=$ 1: Statistical suppression ratio $(S S R)=1.000$, acceptable if $>=0.7$; Nonlinear bivariate causality direction ratio $(N L B C D R)=0.792$, acceptable if $>=0.7$. Estimation: Outer model analysis algorithm: Factor-Based PLS Type REG1; Default inner model analysis algorithm: Warp3; Resampling method used in the analysis: Stable3.

Concluída a avaliação das medidas de qualidade de ajuste do modelo estrutural, segue-se para a análise dos coeficientes e, consequentemente, das hipóteses da pesquisa. De forma a tornar mais explicita a análise, reporta-se, na Tabela 3, o resumo dos resultados:

Tabela 3: Resumo dos resultados das hipóteses de pesquisa.

\begin{tabular}{|c|c|c|c|c|c|c|}
\hline Teoria de suporte & Hipótese & Relacionamento & Tipo de relação & Sinal Esperado & Resultado & Status \\
\hline Pecking Order Theory & $\mathrm{H}_{1}$ & Endividamento -> Desempenho Financeiro & Não linear & - & $-0,222^{* * *}$ & Suportada \\
\hline \multirow{2}{*}{ Teoria de Agência } & $\mathrm{H}_{2}$ & \multirow{2}{*}{$\begin{array}{c}\text { Endividamento -> Valor de Mercado } \\
\text { Endividamento -> Risco }\end{array}$} & Não linear & - & $-0,006$ & $\begin{array}{c}\text { Não } \\
\text { suportada }\end{array}$ \\
\hline & $\mathrm{H}_{3}$ & & Não linear & + & $0,459 * * *$ & Suportada \\
\hline \multirow{3}{*}{$\begin{array}{l}\text { Abordagem Informacional } \\
\text { e Hipótese do Mercado } \\
\text { Eficiente }\end{array}$} & $\mathrm{H}_{4}$ & \multirow{3}{*}{$\begin{array}{l}\text { Desempenho Financeiro -> Valor de } \\
\text { Mercado } \\
\text { Risco -> Desempenho Financeiro } \\
\text { Risco -> Valor de mercado }\end{array}$} & Não linear & + & $0,124^{* * *}$ & Suportada \\
\hline & $\mathrm{H}_{5}$ & & Não linear & - & $-0,112^{* * *}$ & Suportada \\
\hline & $\mathrm{H}_{6}$ & & Não linear & - & $-0,340^{* * *}$ & Suportada \\
\hline \multirow{4}{*}{ Teoria de Agência } & $\mathrm{H}_{7}$ & \multirow{4}{*}{$\begin{array}{c}\text { Governança -> Desempenho Financeiro } \\
\text { Governança -> Valor de Mercado } \\
\text { Endividamento -> Governança } \\
\text { Governança -> Risco }\end{array}$} & Não linear & + & $0,174^{* * *}$ & Suportada \\
\hline & $\mathrm{H}_{8}$ & & Não linear & + & $0,077^{* *}$ & Suportada \\
\hline & $\mathrm{H}_{9}$ & & Não linear & - & $-0.206^{* * *}$ & Suportada \\
\hline & $\mathrm{H}_{10}$ & & Não linear & - & $-0.084^{* *}$ & Suportada \\
\hline
\end{tabular}

Em que: Notas: **,*** Estatisticamente significante ao nível de 0,05 e 0,001 respectivamente.

Fonte: Elaborada'a partir dos dados da pesquisa.

Independentemente dos efeitos do 'Porte'e 'Ano', é possível concluir que'Endividamento' associa-se negativamente ao 'Desempenho Financeiro' $(\beta=-0,222 ; p<0,001)$, confirmando $\mathrm{H}_{1}$; e positivamente ao 'Risco', corroborando $\mathrm{H}_{3}(\beta=0,459 ; \mathrm{p}<0,001)$. Adicionalmente, confirma-se $\mathrm{H}_{4}$ ('Desempenho Financeiro' relaciona-se positivamente com 'Valor de Mercado', $\beta=0,124 ; p<0,001) ; H_{5}$ ('Risco' relaciona-se negativa- 
mente com 'Desempenho Financeiro', $-0,112 ; p<0,001) ; \mathrm{H}_{6}$ ('Risco' relaciona-se negativamente com 'Valor de mercado', $\beta=-0,340 ; p<0,001$ ), $H_{7}$ ('Governança' relaciona-se positivamente com 'Desempenho Financeiro', $\beta=0,174 ; p<0,001), H_{8}$ ('Governança' relaciona-se positivamente com 'Valor de Mercado', $\beta=0,077$; $p<0,05)$ e $H_{9}$ ('Endividamento' relaciona-se negativamente com 'Governança', $\beta=-0,206 ; p<0,001$ ).

Foi notada ainda uma relação não significante entre 'Endividamento' $\mathrm{e}$ 'Valor de Mercado' $(\beta=0.742$; $p<0,001$ ), não permitindo, assim, corroborar $\mathrm{H}_{2}$ (essa relação é analisada mais detalhadamente nas subseções a seguir). Como todas as relações entre os construtos latentes analisados são não lineares, inexiste uma tendência linear global, tendo em vista que o coeficiente de caminho (seja positivo ou negativo) em algum ponto da relação é côncavo (Kock, 2015). Em outras palavras, não é possível concluir, por exemplo, que um crescimento exponencial de 'Governança' acarretará, sempre, na redução do 'Risco' da firma $\left(\mathrm{H}_{10}\right)$.

Torna-se relevante, também, avaliar o efeito total dos construtos latentes compreendidos no modelo estrutural proposto sobre a variável endógena alvo, 'Valor de Mercado'. Os resultados do efeito total são reportados na Tabela 4:

Tabela 4: Efeito Total dos construtos latentes sobre a variável endógena alvo

\begin{tabular}{|c|c|c|c|c|c|c|c|}
\hline & Gov & Risco & DesFin & Endiv & VM & Porte & Ano \\
\hline Gov & & & & $-0,206^{* * *}$ & & & \\
\hline Risco & $-0,084^{* *}$ & & & $0,476^{* * *}$ & & & \\
\hline DesFin & $0,184^{* * *}$ & $-0,112^{* *}$ & & $-0,312^{* * *}$ & & & \\
\hline Endiv & & & & & & $0,65^{* * *}$ & $-0,092^{* *}$ \\
\hline VM & $0,129^{* * *}$ & $-0,353^{* * *}$ & $0,124^{* * *}$ & $-0,222^{* * *}$ & & & \\
\hline Porte & & & & & & & \\
\hline Ano & & & & & & & \\
\hline
\end{tabular}

Fonte: Elaborada a partir dos dados da pesquisa

Conforme apresentado na Tabela 4, nota-se que'Porte' apresenta o maior impacto sobre o construto 'Valor de mercado', tendo em vista o coeficiente padronizado de 0,65 , seguido do construto 'Risco' (coeficiente de -0,353), 'Endividamento' (coeficiente de -0,222), Governança (coeficiente de 0,129), 'Desempenho Financeiro' (coeficiente de 0,124) e, por fim, Ano (coeficiente de -0,092).

Analisando os tamanhos e significância dos coeficientes de caminho do modelo externo, conclui-se que 'Governança' apresenta um efeito direto mais forte sobre 'Desempenho Financeiro' $(\beta=0,17, p<$ $0,001)$ do que propriamente sobre'Valor de mercado' $(\beta=0,08, p<0,001)$, indicando que a implantação das boas práticas de governança contribui mais significativamente para o incremento do peformance da firma, através do incremento da eficiência e eficácia das operações (Ulum et al., 2014) do que propriamente à percepção, por parte do mercado, de agregação de valor da firma em decorrência das boas práticas de governança.

Esse insight fica ainda mais evidente quando conclui-se que o 'Desempenho Financeiro' exerce papel mediador significante da relação entre 'Governança' e 'Valor de mercado' (coeficiente de 0,129), assim, conclui-se que as boas práticas de 'Governança', além de apresentarem um efeito direto sobre 'Valor de mercado' (conforme discutido anteriormente), ao incrementar o desempenho das operações, tem seu efeito total sobre 'Valor de mercado' incrementado significativamente.

Outra análise importante ocorre na conclusão de que 'Risco' é, dentre os construtos estudados, o que exerce maior efeito sobre 'Valor de mercado' $(\beta=-0,34, p<0,001)$, seguido de bem longe por 'Desempenho Financeiro' $(\beta=0,12, p<0,001)$, resultado que indica uma preocupação maior em evitar perdas em detrimento de maximizar ganhos, refletindo, assim, o perfil de aversão ao risco existente no investidor brasileiro. 


\subsection{Análise das hipóteses após controle do tamanho das empresas}

Concluída a análise da amostra completa (compreendendo todas as 639 observações), buscou-se avaliar o comportamento das hipóteses de pesquisa após o controle do porte das firmas e do período (ano) através de análise multigrupo (PLS-SEM multigroup analysis- PLS-MGA). Nesse aspecto, utilizando o Logaritmo natural do Ativo Total, a amostra foi segregada em dois grupos: empresas menores (observações abaixo da mediana, grupo 01) e empresas maiores (observações acima da mediana, grupo 02). Nessa etapa da pesquisa, notou-se que algumas hipóteses confirmadas anteriormente $\left(\mathrm{H}_{1}, \mathrm{H}_{3} \mathrm{e} \mathrm{H}_{4}\right)$ são corroboradas para ambos os grupos de empresas, no entanto, a H10, de relacionamento negativo entre 'Governança'e'Risco', foi suportada, apenas, para a amostra composta por empresas de pequeno porte, sugerindo que, para estas, ainda há benefícios marginais decorrentes da implantação de práticas de governança, sobretudo, relacionados à menor probabilidade de ocorrência de fraudes nas operações e maior compliance. Já para as empresas de maior porte, houve inversão de sinal, sendo, possivelmente, reflexo do envolvimento (e/ou denúncias) de grandes corporações (reconhecidamente com melhores indicadores de 'Governança') em uma série de escândalos no período (Operações Zelotes e Lava Jato, sobretudo), como, por exemplo, Petrobrás, Gerdau, Marcopolo, Braskem, TIM, Embraer, Eletrobrás, além de incorporadoras e construtoras, montadoras automobilísticas, entre outras.

$A H_{2^{\prime}}$ de relação negativa entre 'Endividamento' $e^{\prime}$ Valor de Mercado' $(\beta=-0,242 ; p<0,001)$, foi suportada apenas por empresas de grande porte, refletindo, assim, um maior e mais efetivo monitoramento por parte dos acionistas das maiores empresas, que questionam, em resposta à assimetria informacional, os motivos à não utilização de recursos gerados internamente em detrimento da captação externa, acarretando numa subavaliação das ações e, consequentemente, na perda de valor para os acionistas em resposta à decisão de incremento da dívida (Medeiros \& Daher, 2008). Adicionalmente, ao aumentar a dívida, incrementa-se o risco para os acionistas, que, em resposta, exigem maior taxa de desconto, o que, ao trazer a valor presente o fluxo de caixa futuro a uma taxa maior, acarreta em uma redução do valor da ação e da empresa. Relativo às empresas de menor porte, houve, mais uma vez, mudança do sinal, indicando que os benefícios fiscais (Modigliani \& Miller, 1963), e a percepção, por parte dos acionistas, desta contratação como um indicativo do potencial de alavancar as operações, afetam positivamente o valor das empresas. É importante ressaltar que o modelo estrutural proposto apresenta capacidade explicativa da variável endógena de interesse, 'Valor de Mercado', significativamente superior para empresas de grande porte $\left(R_{2}\right.$ de 0,81$)$.

No grupo das empresas de maior porte, a $\mathrm{H}_{5}$ ' de relação negativa entre 'Risco' e 'Desempenho Financeiro', também encontra respaldo. A evidência empírica sobre a relação entre risco e o desempenho financeiro das firmas desde o trabalho seminal de Jensen e Meckling (1976), tem apresentado resultados inconclusivos. No cenário notado no presente estudo, argumenta-se que as firmas de maior porte parecem ter alcançado níveis de alavancagem que, em resposta à instabilidade econômica e política do período, afetaram negativamente seus desempenhos. Já para as empresas de menor porte, a relação positiva pode indicar a existência de margem para incremento do risco sem comprometer o desempenho.

Na relação entre 'Risco' e 'Valor de mercado' $\left(\mathrm{H}_{6}\right)$, também houve comportamento distinto (com mudança de sinal) entre as empresas dos dois grupos. $\mathrm{A}_{6}$ foi confirmada na amostra composta por empresas de pequeno porte, reforçando a ideia de que, muito embora o maior risco assumido pelas empresas de pequeno porte acarrete em maiores desempenhos financeiros, o incremento marginal de desempenho não é suficiente para compensar o risco assumido, o que se reflete no sinal negativo apresentado na relação entre 'Risco' e alteração do 'valor de mercado' dessas firmas. Já a relação positiva obtida na amostra composta por empresas de grande porte, conjectura-se que, muito embora o 
incremento do risco apresente relação negativa com o desempenho financeiro presente, esse efeito é entendido, pelos investidores, como transitório, em resposta à instabilidade econômica e política. Em outras palavras, o mercado reconhece que, no médio o longo prazo, a assunção de risco acarretará no incremento dos resultados futuros, gerando, assim, uma expectativa positiva por parte dos acionistas que eleva o valor de mercado das mesmas.

A relação positiva entre 'Governança' $\mathrm{e}$ 'Desempenho Financeiro' $\left(\mathrm{H}_{7}\right)$, foi suportada apenas por empresas de menor porte, o que pode refletir que, em firmas de maior porte, todo o ganho de eficiência advindo da implantação de boas práticas de governança já foi efetivamente refletido no desempenho presente, não sendo, nesse aspecto, alcançado efeito marginal (o que não ocorreria nas empresas menores que, em tese, ainda têm margem para ganho de eficiência proveniente da implantação de boas práticas de governança).

$\mathrm{A}_{8^{\prime}}$ de relação positiva entre 'Governança' e'Valor de mercado', mostrou-se suportada apenas nas empresas de maior porte. Nesse caso, esse comportamento pode refletir o entendimento, por parte do acionista, que, essas empresas trabalham muito próximas da fronteira máxima de eficiência, têm baixo custo de capital, maior competitividade, elevado crescimento de vendas, maior probabilidade de realizar aquisições corporativas, acarretando, assim, em maior valor de mercado. Já no caso das empresas de menor porte, a relação não significante pode indicar que, muito embora essas firmas tenham margem para ganho de eficiência em resposta às boas práticas de governança corporativa, não existem expectativas que estas sejam implantadas no curto período de tempo.

Por fim, alinhado ao resultado obtido na análise com a amostra completa, o relacionamento negativo esperado entre 'Endividamento' e 'Governança' $\left(\mathrm{H}_{9}\right)$ foi alcançado independentemente do porte das firmas, indicando a existência do um efeito substituição decorrente da redução dos investimentos da implantação de melhores mecanismos de governança em resposta aos maiores esforços de monitoramento realizados por parte dos detentores da dívida. Nesse cenário, a percepção, por parte dos investidores, da existência de investimentos exagerados (overinvestment) pode estar sendo incorporada à taxa cobrada pelos recursos financeiros, reduzindo, assim o valor da empresa.

Ademais, esse resultado também pode ser justificado pela característica do mercado acionário brasileiro (empresas familiares, concentração de propriedade nas mãos do controlador, existência de estruturas piramidais de controle, entre outros) que reduz significativamente o alcance dos benefícios decorrentes da implantação de boas práticas de governança corporativa. Em resposta a esse cenário, os credores monitoram a peformance das firmas por meio de outros dispositivos/métodos, tendo, nesse aspecto, baixo enforcement para a implantação de mecanismos de governança corporativa nas firmas brasileiras.

\section{4 .4 Análise das hipóteses após controle da variável 'ano'}

Concluindo as análises, verificou-se, após o controle da variável'ano', o comportamento das hipóteses de pesquisa longitudinalmente. Acerca das relações de 'Governança', notou-se consistência apenas com 'Risco' $\left(\mathrm{H}_{10}\right)$, nos anos de 2013 e 2014, e com 'Desempenho Financeiro', $\mathrm{H}_{7}$, no ano de 2013. A $\mathrm{H}_{3}$ ('Endividamento' e 'Risco'), pôde ser corroborada no triênio, enquanto $\mathrm{H}_{2}$ ('Endividamento' e 'Valor de Mercado') e $\mathrm{H}_{1}$ ('Endividamento' e 'Desempenho Financeiro') foram suportadas apenas nos anos de

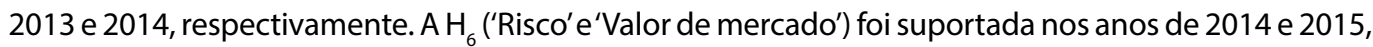
sendo, no entanto, notado o suporte de $\mathrm{H}_{5}$ ('Risco' e'Desempenho Financeiro') para os anos de $2013 \mathrm{e}$ 2015. Nesse aspecto, pode-se concluir que, no período em questão, a volatilidade política e econômica influenciou, de forma significativa, as relações teóricas previstas entre os construtos em análise, sendo, nesse aspecto, imprescindível o controle do tempo por parte de pesquisas correlatas. 


\subsection{Teste de Robustez via Robust Path Analysis}

Buscando obter maior robustez dos resultados, foi conduzida uma segunda análise via Robust Path Analysis, que, quando comparada a técnica PLS-SEM, a Robust Path Analysis mostra-se mais parcimoniosa, tendo em vista que são trabalhadas apenas uma proxy para cada construto em detrimento do conjunto de indicadores formativos.

Após o controle de 'Porte' e 'Ano', corrobora-se os achados de relação significativa entre 'Endividamento' e 'Desempenho Financeiro' $\left(\beta=-0,135 ; p<0,001 ; f^{2}=0,014 ; H_{1}\right)$; 'Endividamento' e 'Valor de Mercado' $\left(\beta=-0,073 ; p<0,05 ; f^{2}=0,026 ; H_{2}\right) ;{ }^{\prime}$ Endividamento' e 'Risco' $\left(\beta=0,352 ; p<0,001 ; f^{2}=0,134 ; H_{3}\right)$; 'Risco' e'Valor de mercado' $\left(\beta=-0,223 ; p<0,001 ; f^{2}=0,116 ; H_{6}\right)$;'Governança' e 'Desempenho Financeiro' $\left(\beta=0,054 ; p<0,05 ; f^{2}=0,002 ; H_{7}\right) ;{ }^{\prime} G o v e r n a n c ̧ a '$ e Valor de Mercado' $\left(\beta=0,101 ; p<0,01 ; f^{2}=0,037 ; H_{8}\right)$ e 'Governança' e'Risco' $\left(\beta=-0,129 ; p<0,001 ; f^{2}=0,027 ; H_{10}\right)$.

Não foi possível corroborar os relacionamentos entre 'Desempenho Financeiro' e'Valor de Mercado' $\left(\mathrm{H}_{4}\right)$; 'Risco' e 'Desempenho Financeiro' $\left(\mathrm{H}_{5}\right)$; e entre 'Endividamento' e 'Governança' $\left(\mathrm{H}_{9}\right)$. No caso das relações previstas por $\mathrm{H}_{4}$ e $\mathrm{H}_{5^{\prime}}$ argumenta-se que a não significância pode ser resultado da dificuldade inerente à operacionalização do construto 'Desempenho Financeiro' através de um único indicador capaz de capturar todo o seu conteúdo. Por fim, relativo ao relacionamento teorizado em $\mathrm{H}_{9^{\prime}}$ a não significância estatística encontra-se coerente aos resultados obtidos na análise PLS-SEM, conforme já discutido anteriormente.

\section{CONSIDERAÇÕES FINAIS}

O presente estudo contribui para expandir a compreensão das relações simultâneas de dependência e independência entre governança corporativa, risco e endividamento no desempenho financeiro e no valor de mercado das firmas brasileiras listadas na BM\&FBOVESPA no período de 2013 a 2015. Utilizou-se, para tal verificação, a técnica de Equações Estruturais em Mínimos Quadrados Parciais, em escalas de mensuração formativas e com o algoritmo baseado em fator (Factor-Based PLS Type REG1), em decorrência do relacionamento não linear existente entre os construtos latentes.

Pode-se notar que, independentemente do'Porte' e do 'Ano', existe um consistente relacionamento, conforme previsto pela teoria, entre 'Endividamento' e 'Desempenho Financeiro' $\left(H_{1}\right)$, 'Endividamento' e 'Risco' $\left(H_{3}\right)$,'Desempenho Financeiro' e 'Valor de Mercado' $\left(H_{4}\right)$, 'Risco' e 'Desempenho Financeiro' $\left(H_{5}\right)$, 'Risco' e 'Valor de mercado' $\left(\mathrm{H}_{6}\right)$, 'Governança' e 'Desempenho Financeiro' (H7), 'Governança' e 'Valor de Mercado' $\left(H_{8}\right)$,'Governança'e'Risco' $\left(H_{10}\right)$ e'Governança' $e^{\prime}$ Endividamento' $(\beta=-0.206 ; p<0,001)$. Foi notada ainda uma relação não significante entre 'Endividamento' $e^{\prime} V a l o r$ de Mercado' $(\beta=0.742 ; p<0,001)$, não permitindo, assim, corroborar $\mathrm{H}_{2}$.

Outro insight relevante emerge da necessidade de considerar o efeito conjuntural do mercado/ ambiente econômico nas análises sobre as relações entre os construtos analisados. Aparentemente, a turbulência do mercado (crise política, aumento do desemprego, redução do crescimento da economia, seguidos déficits fiscais, aumento da cotação dólar consubstanciados à elevação do custo de captação de recursos, decorrente do incremento da taxa básica de juros e o rebaixamento da nota de crédito do país e das empresas por parte das agências de risco) apresentou influência significativa nos resultados.

Por meio do controle da variável 'Ano', foi possível notar que a instabilidade política e econômica, de forma significativa e sistemática, apresenta potencial de alterar as relações teóricas, sendo, imprescindível nesse aspecto, efetuar o controle do tempo quando o interesse for capturar, efetivamente, as complexas relações simultâneas de dependência e independência entre Governança Corporativa, Risco, Estrutura de Capital, Desempenho e Valor da firma. 
A título de limitações, o período compreendido na pesquisa (2013 a 2015), por apresentar importante turbulência econômica e política no país, eventualmente, pode influenciar a força (intensificar ou atenuar) dos relacionamentos. Outra limitação surge dos indicadores selecionados que, eventualmente, podem não compreender a amplitude da cobertura dos construtos, não garantindo, necessariamente, a captura plena dos seus conteúdos. Nesse aspecto, esforços podem ser direcionados para a condução de estudos correlatos utilizando-se de outros períodos de análise e proxy's.

Especificamente sobre o construto 'Governança', a avaliação de sua validade pode ser suportada por meio da utilização de subcategorias, compreendendo as dimensões de governança corporativa costumeiramente trabalhadas na literatura (e.g., direito dos acionistas, ética e conflito de interesses, conselho de administração e transparência).

\section{REFERÊNCIAS}

Adi, Tri Wahyu, Siti, Ragil H. Suhadak, \& Rahayu, Sri Mangesti (2013). Risk, Financial Performance and Firm Value: A Study on the Mining Company Listed in Indonesia Stock Exchange in 2009-2012. European Journal of Business and Management, 5(29).

Assaf Neto, A. (2012). Finanças Corporativas e Valor. São Paulo: Atlas.

Ball, R., \& Brown, P. (1968). An empirical evaluation of accounting income numbers. Journal of accounting research, 159-178. doi:10.2307/2490232

Beaver, W. H., Clarke, R., \& Wright, W. F. (1979). The association between un systematic security returns and the magnitude of earnings forecast errors. Journal of Accounting Research, 316-340. doi: $10.2307 / 2490507$

Berle, A.; Means, G. (1932). The Modern Corporation and Private Property. New York: Macmillan.

Ben-Zion, U. (1978). The investment aspects of non-productive expenditures: an empirical test. Journal of Economics and Business, 30, 224-229.

Black, B., Jang, H., \& Kim, W. (2003). Does Corporate Governance Affects Firms' Market values? Evidence from Korea. Journal of Law, Economics and Organization, 22(2), 1-48. doi: 10.1093/jleo/ewj018

Brown, P. (1970). The impact of the annual net profit report on the stock market.The Australian Accountant, 60(3), 277-283.

Chin, W.W. (1998). The partial least squares approach to structural equation modeling. In G. A. Marcoulides (Ed.), Modern methods for business research (p. 295-358). Mahwah, NJ: Lawrence Erlbaum.

Chung, K. H., Wright, P., \& Kedia, B. (2003). Corporate governance and market valuation of capital and R\&D investments. Review of Financial Economics, 12(2), 161-172. doi: 10.1016/S1058-3300(02)00063-0

Damodaran, A. (2002). Finanças corporativas aplicadas. Porto Alegre: Bookman.

Demsetz, H., \& Villalonga, B. (2001). Ownership structure and corporate performance. Journal of corporate finance, $7(3), 209-233$. doi: 10.2139/ssrn.266101

Diamantopoulos, A., \&Winklhofer, H. M. (2001). Index construction with formative indicators: An alternative to scale development. Journal of Marketing Research, 38, 269-277. doi: 10.1509/jmkr.38.2.269.18845

Diamantopoulos, A., Riefler, P., \& Roth, K. P. (2008). Advancing formative measurement models.Journal of Business Research, 61, 1203-1218. doi:10.1016/j.jbusres.2008.01.009 
Diamantopoulos, A., Sarstedt, M., Fuchs, C., Kaiser, S., \& Wilczynski, P. (2012). Guidelines for choosing between multi-item and single-item scales for construct measurement: A predictive validity perspective. Journal of the Academy of Marketing Science, 40, 434-449. doi: 10.1007/s11747-011-0300-3

Hall, B. H. (1993). The stock market's valuation of R\&D investment during the 1980's. American Economic Review, 83, 259-264.

Hirschey, M. (1982). Intangible capital aspects of advertising and R\&D expenditures. Journal of Industrial Economics, 30, 375-390. doi: 10.2307/2097924

Fama, E. F. (1991). Efficient capital markets: II.The journal of finance, 46(5), 1575-1617. doi: 10.1111/j.15406261.1991.tb04636.x

Fama, E. F., \& French, K. R. (1998). Taxes, financing decisions, and firm value. The Journal of Finance, 53(3), 819-843. doi: 10.1111/0022-1082.00036

Fama, E. F., \& French, K. R. (2002). Testing trade-off and pecking order predictions about dividends and debt. Review of Financial Studies, 15(1), 1-33. doi: 10.1093/rfs/15.1.1

Firth, M. (1981). The relative information content of the release of financial results data by firms. Journal of Accounting Research, 521-529. doi: 10.2307/2490878

Foster, G. (1975). Accounting earnings and stock prices of insurance companies. Accounting Review, 686-698.

Fuchs, C., \& Diamantopoulos, A. (2009). Using single-item measures for construct measurement in management research: Conceptual issues and application guidelines. Die Betriebswirtschaft, 69, 197-212.

Gompers, P. A., Ishii, J. L., \& Metrick, A. (2003). Corporate governance and equity prices. Quarterly Journal of Economics, 118(1), 107-155. doi: 10.1162/00335530360535162

Hair Jr, J. F., Hult, G. T. M., Ringle, C., \& Sarstedt, M. (2014). A primer on partial least squares structural equation modeling (PLS-SEM). Sage Publications.

lquiapaza, R. A., Amaral, H. F., \&Araújo, M. D. S. B. D. (2008). Testing the Pecking Order Theory forecasts in Brazilian companies financing: a new methodology. RAM. Revista de Administração Mackenzie, 9(3), 157-183. doi: 10.1590/S1678-69712008000300008.

Jensen, M. C., \& Meckling, W. H. (1976). Theory of the firm: Managerial behavior, agency costs and ownership structure. Journal of financial economics, 3(4), 305-360. doi: 10.1007/978-94-009-9257-3_8

Jiraporn, P., \& Gleason, K. C. (2007). Capital Structure, Shareholder Rights and Corporate Governance. Journal of Financial Research, 30: 21-33. doi:10.1111/j.1475-6803.2007.00200.x

Jose, M. L., Nichols, L. M., \& Stevens, J. (1986). Contributions of diversification, promotion, and R\&D to the value of multiproduct firms: a Tobin's q approach. Financial Management, 15, 33-42. doi: $10.2307 / 3665778$

Klapper, L. F., \& Love, I. (2004). Corporate governance, investor protection, and performance in emerging markets. Journal of corporate Finance, 10(5), 703-728. doi: 10.1080/17938120.2014.886421

Kock, Ned. WarpPLS 5.0 user manual. Laredo, TX: ScriptWarp Systems, 2015. 
Kraus, A., Litzenberger, R. H. (1973). A State-preference model of optimal financial leverage. The Journal of Finance, 28, 911-922. doi:10.1111/j.1540-6261.1973.tb01415.x

Lameira, V. J. (2012). As Relações Entre Governança e Risco nas Companhias Abertas Brasileiras. Revista Brasileira de Gestão de Negócios, 14(42), 7-25. doi: 10.7819/rbgn.v14i42.871

Medeiros, O. R. D., \&Daher, C. E. (2008). Testando teorias alternativas sobre a estrutura de capital nas empresas brasileiras. Revista de Administração Contemporânea, 12(1), 177-199. doi: 10.1590/S141565552008000100009

Modigliani, F., \& Miller, M. H. (1958). The cost of capital, corporation finance and the theory of investment. The American economic review, 48(3), 261-297.

Modigliani, F., \& Miller, M. H. (1963). Corporate income taxes and the cost of capital: a correction. The American Economic Review, 53(3), 433-443.

Mule, R. K., \& Mukras, M. S. (2015). Financial Leverage and Performance of Listed Firms in a Frontier Market: Panel Evidence From Kenya. European Scientific Journal, 11(7), 534-550.

Myers, S. C., \& Majluf, N. (1984). Corporate financing and investment decisions when firms have informations that investors do not have. Journal of Financial Economics, 13(2), 187-221. doi: 10.3386/w1396

Pearl, J. (2009). Causality: Models, reasoning, and inference. Cambridge, England: Cambridge University Press.

Prasetyo, A. H. (2011). Corporate Governance and Systematic Risk: Evidence from Indonesia Listed Company. In: International Conference on Economics and Finance Research, Singapore.

Rodgers, W. (1999).The influences of conflicting information on novices' and loan officers' actions. Journal of Economic Psychology, 20, 123-145.doi: 10.1016/S0167-4870(99)00002-1

Sami, H., Wang, J., \& Zhou, H. (2011). Corporate governance and operating performance of Chinese listed firms. Journal of International Accounting, Auditing and Taxation, 20(2), 106-114.doi: 10.1016/j. intaccaudtax.2011.06.005

Sanvicente, A. Z. (1991). O custo de imperfeições do mercado brasileiro de capitais: uma aplicação da moderna teoria de finanças. Revista de Administração de Empresas, 31(1), 15-20. doi: 10.1590/S003475901991000100003

Silva, A. L. C. (2005).Governança corporativa e decisões financeiras no Brasil. Rio de Janeiro: Mauad Editora Ltda.

Silveira, A. D. M. (2015). Governança corporativa no Brasil e no mundo: teoria e prática. Rio de Janeiro: Elsevier Brasil.

Smith, D., \&Langfield-Smith, K. (2004). Structural equation modelling in management accounting research: critical analysis and opportunities. Journal of Accounting Literature, 23, 49-86.

Smith, M. (2003).Research Methods in Accounting. SAGE Publications: London.

Tabachnick, B., \& Fidell, L. (1996). Using multivariate statistics. New York: Harper Collins College Publishers.

Tirole, J. (2010). The theory of corporate finance.Princeton University Press. 
Ulum, Z. K. A. B., Wafa, S. A. W. S. K., Karim, M. R. A., \& Jamal, A. A. A. (2014). Corporate Governance Practices of Insurance Companies: Attributes and Accountability. IUP Journal of Corporate Governance, 13(1), 47-57.

Wagner, C. H. (1982). Simpson's paradox in real life. The American Statistician, 36, 46-48.

Weston, J. F., \& Brigham, E. F. (2000). Fundamentos da Administração Financeira. 10. ed., São Paulo: Makron Books. 